\title{
Epidemic Myalgia Associated with Human Parechovirus Type 3 Infection
}

\author{
Moemi Miyazaki ${ }^{1}$, Kenta Hara ${ }^{2}$, Tomofumi Takayoshi ${ }^{2}$, Tetsuya Kawase ${ }^{2}$, \\ Yasushi Nakagawa ${ }^{2}$, Takashi Arai ${ }^{1}$, Takeshi Sugimoto ${ }^{3}$, Katsuhito Nishiyama ${ }^{1}$, \\ Gabriel Gonzalez ${ }^{4}$, Nozomu Hanaoka ${ }^{5}$, Tsuguto Fujimoto ${ }^{5}$, \\ Yoshiro Yasutomo ${ }^{1}$ and Koichi Yokono ${ }^{1}$
}

\begin{abstract}
:
A 42-year-old man was hospitalized due to a fever, orchiodynia, and extremely severe myalgia predominantly in the extremities, which made it difficult for him to stand or walk. He had a history of contact with his son who had acute upper respiratory infection. Based on the characteristic clinical symptoms and detection of the partial sequence of human parechovirus type 3 (HPeV3) in throat swabs as well as stool and serum samples, he was diagnosed with epidemic myalgia associated with HPeV3 infection. Because HPeV3 infection is widespread among children in Japan, HPeV3-associated myalgia should be considered when adult patients manifest such distinguishing clinical characteristics.
\end{abstract}

Key words: epidemic myalgia, human parechovirus type 3, viral infectious disease

(Intern Med 59: 739-744, 2020)

(DOI: 10.2169/internalmedicine.3326-19)

\section{Introduction}

Epidemic myalgia, also known as Bornholm disease, is a viral infectious disease that was first reported by Ejnar Sylvest in the 1930s $(1,2)$. It was named after the Danish island of Bornholm, where its outbreak was reported for the first time. It is characterized by the sudden onset of extreme pain in the chest or upper abdomen, sometimes associated with a fever or sore throat. Coxsackievirus and Echovirus have been implicated in the pathogenesis of this disease (3). In 2008, epidemic myalgia associated with human parechovirus type 3 (HPeV3) was reported in Yamagata, Japan (4). Subsequently, HPeV3-associated myalgia was reported in Osaka City and Kanagawa Prefecture in adults as well as in children $(5,6)$. Whereas mild myalgia is frequently caused by viral infection, epidemic myalgia associated with $\mathrm{HPeV} 3$ infection can be distinguished from such common viral-associated symptoms based on its characteris- tic symptoms of extreme myalgia and muscular weakness predominantly affecting the proximal muscles of the upper and lower extremities (4).

$\mathrm{HPeV}$ is a positive-sense, single-stranded RNA virus that belongs to the family Picornaviridae (7). Thus far, more than 10 genotypes of $\mathrm{HPeV}$ have been identified (8). HPeV1 and HPeV2 were previously known as echovirus 22 and echovirus 23, respectively, and have been now reclassified as members of Parechovirus. HPeV3 was first identified in 2004 from a one-year-old child with transient paralysis, a fever, and diarrhea in Japan (9). HPeV infections, such as those associated with HPeV1, HPeV2, and HPeV4-8, mostly cause mild gastroenteritis and respiratory infections early in life; however, HPeV3 infection is associated with more serious illnesses, such as sepsis-like syndrome or encephalitis as well as mild gastroenteritis and respiratory infections in neonates and young infants (10-12).

Although HPeV3 infection is widespread among children in Japan, epidemic myalgia associated with $\mathrm{HPeV} 3$ infection

\footnotetext{
${ }^{1}$ Department of Internal and Geriatric Medicine, Kita-Harima Medical Center, Japan, ${ }^{2}$ Department of Diabetes and Endocrine Disease, KitaHarima Medical Center, Japan, ${ }^{3}$ Department of Hematology and Oncology, Kita-Harima Medical Center, Japan, ${ }^{4}$ Research Center for Zoonosis Control, Hokkaido University, Japan and ${ }^{5}$ Infectious Disease Surveillance Center, National Institute of Infectious Diseases, Japan Received: May 11, 2019; Accepted: September 9, 2019; Advance Publication by J-STAGE: October 31, 2019 Correspondence to Dr. Kenta Hara, harakkobe@gmail.com
} 
Table 1. Laboratory Findings on Admission.

\begin{tabular}{|c|c|c|c|}
\hline & This patient (Normal range) & & This patient (Normal range) \\
\hline $\mathrm{WBC}(/ \mu \mathrm{L})$ & $5,050(3,500-9,700)$ & $\mathrm{BUN}(\mathrm{mg} / \mathrm{dL})$ & $12.5(8.0-20.0)$ \\
\hline Neut $(\%)$ & $72.4(38.0-74.0)$ & $\operatorname{Cre}(\mathrm{mg} / \mathrm{dL})$ & $0.98(0.6-1.1)$ \\
\hline $\operatorname{Eos}(\%)$ & $2.8(0.0-8.5)$ & $\mathrm{CRP}(\mathrm{mg} / \mathrm{dL})$ & $2.3(<0.30)$ \\
\hline Baso $(\%)$ & $0.4(0.0-2.5)$ & $\mathrm{PG}(\mathrm{mg} / \mathrm{dL})$ & $98(70-109)$ \\
\hline Mono $(\%)$ & $9.5(2.0-10.0)$ & $\mathrm{Na}(\mathrm{mEq} / \mathrm{L})$ & $138(135-146)$ \\
\hline Lymph (\%) & $14.9(16.5-49.5)$ & $\mathrm{K}(\mathrm{mEq} / \mathrm{L})$ & $4.4(3.5-5.0)$ \\
\hline $\mathrm{RBC}(/ \mu \mathrm{L})$ & $527 \times 10^{4}\left(400-550 \times 10^{4}\right)$ & $\mathrm{Cl}(\mathrm{mEq} / \mathrm{L})$ & $103(96-108)$ \\
\hline $\mathrm{Hb}(\mathrm{g} / \mathrm{dL})$ & $16.2(13.2-17.2)$ & $\mathrm{Ca}(\mathrm{mg} / \mathrm{dL})$ & $10.1(8.7-11.0)$ \\
\hline $\operatorname{Hct}(\%)$ & $49.9(40-52)$ & $\mathrm{P}(\mathrm{mg} / \mathrm{dL})$ & $4.1(2.5-4.5)$ \\
\hline Plt $(/ \mu \mathrm{L})$ & $27.5 \times 10^{4}\left(14-37 \times 10^{4}\right)$ & $\mathrm{Mg}(\mathrm{mg} / \mathrm{dL})$ & $2.1(1.8-2.4)$ \\
\hline AST (IU/L) & $38(13-33)$ & $\mathrm{fT} 4$ (ng/dL) & $0.80(0.70-1.48)$ \\
\hline ALT (IU/L) & $70(8-42)$ & $\mathrm{TSH}(\mu \mathrm{IU} / \mathrm{mL})$ & $1.93(0.35-4.94)$ \\
\hline ALP (IU/L) & $340(115-359)$ & $\operatorname{ESR}(\mathrm{mm} / \mathrm{h})$ & $5(1-10)$ \\
\hline$\gamma$-GT (IU/L) & $126(10-47)$ & ANA & Negative \\
\hline LDH (IU/L) & $185(119-229)$ & HBs Ag & Negative \\
\hline $\mathrm{CK}(\mathrm{IU} / \mathrm{L})$ & $238(62-287)$ & $\mathrm{HBs} \mathrm{Ab}$ & Negative \\
\hline $\mathrm{TP}(\mathrm{g} / \mathrm{dL})$ & $7.3(6.7-8.3)$ & $\mathrm{HBc} \mathrm{Ab}$ & Negative \\
\hline $\mathrm{Alb}(\mathrm{g} / \mathrm{dL})$ & $4.3(3.9-4.9)$ & $\mathrm{HCV} \mathrm{Ab}$ & Negative \\
\hline
\end{tabular}

Neut: neutrophils, Eos: eosinophils, Baso: basophils, Mono: monocytes, Lymph: lymphocytes, RBC: red blood cell, Hct: hematocrit, Plt: platelet, AST: aspartate aminotransferase, ALT: alanine aminotransferase, ALP: alkaline phosphatase, $\gamma$-GT: gamma-glutamyltransferase, LDH: lactate dehydrogenase, CK: creatine kinase, TP: total protein, Alb: albumin, BUN: blood urea nitrogen, Cre: creatinine, CRP: C-reactive protein, PG: plasma glucose, Na: sodium, K: potassium, Cl: chlorine, Ca: calcium, P: phosphorus, Mg: magnesium, fT4: free thyroxine 4, TSH: thyroid stimulating hormone, ESR: erythrocyte sedimentation rate, ANA: anti-nuclear antibody, HBs: hepatitis B surface, $\mathrm{HBc}$ : hepatitis B core, $\mathrm{HCV}$ : hepatitis $\mathrm{C}$ virus, Ag: antigen, Ab: antibody

has been reported among adults and children from limited areas of Japan; thus, it was once referred to as an "unusual outbreak" in Japan (8). This might be, at least in part, because of the difficulty in accurately diagnosing epidemic myalgia associated with $\mathrm{HPeV} 3$ infection, due to the lack of awareness of this disease. Therefore, we present the case of a patient with epidemic myalgia and a confirmed $\mathrm{HPeV} 3$ infection.

\section{Case Report}

A 42-year-old man presented to the Department of Internal Medicine of our hospital in a wheelchair owing to extremely severe muscle pain and weakness, primarily in the arms and legs, in July 2016. The pain was so severe that he was unable to stand and walk; therefore, he was admitted to our hospital. He had been well until two days before this presentation, when he began to experience sore throat and muscle pain. Approximately two weeks before the appearance of these symptoms, his three-year-old son had presented with an acute upper respiratory infection, which improved within a few days. The patient had no history of medication or allergies.

On admission to our hospital, the height, weight, and body mass index (BMI) of the patient were $170.4 \mathrm{~cm}, 90$ $\mathrm{kg}$, and $31.1 \mathrm{~kg} / \mathrm{m}^{2}$, respectively. A physical examination revealed that he was alert; his blood pressure was 139/90 $\mathrm{mmHg}$, pulse rate was regular at 90 beats per minute, body temperature was $39.5^{\circ} \mathrm{C}$, and respiratory rate was 14 breaths per minute. He showed a red pharynx, swollen tonsils, and no palpable lymph nodes. His thyroid gland was elastic-soft with no swelling, nodules, or tenderness. Cardiac and respiratory sounds were normal, and an abdominal examination revealed no abnormalities. He had severe myalgia and muscle weakness predominantly involving the four extremities; however, no redness, swelling, or local warmth was noted. He had no rashes or abnormal joint findings; however, he had orchiodynia. Laboratory findings on admission are shown in Table 1.

The lymphocytopenia appeared to be associated with the virus infection. The CRP level remained the same $(2.72 \mathrm{mg}$ / $\mathrm{dL}$ ) the day after admission, and it was not followed up further because the symptoms improved in the patient. The AST, ALT, and $\gamma$-GTP levels showed a decreasing trend (33 IU/L, $67 \mathrm{IU} / \mathrm{L}$, and $124 \mathrm{IU} / \mathrm{L}$, respectively) the next day, and an ultrasound scan of the abdomen revealed a fatty liver.

Epidemic myalgia caused by $\mathrm{HPeV} 3$ infection was suspected on the basis of the predominant pain in his limbs as well as symptoms related to acute upper respiratory infection and orchiodynia (4), although we did not further evaluate the testis because no physical findings, such as redness or swelling, were observed in the scrotum. To confirm the diagnosis of epidemic myalgia associated with $\mathrm{HPeV} 3$ infection, a part of the viral ribonucleic acid (RNA) sequence was amplified from serum samples collected on the second day after admission and from throat swabs and stool sam- 
ples collected on the third day after admission. A polymerase chain reaction (PCR)-sequencing analysis was performed after obtaining informed consent from the patient. First, RNA was extracted from the samples and used to synthesize first-strand complementary deoxyribonucleic acid (cDNA). Subsequently, nested PCR was performed to amplify the junctional region of capsid-protein encoding VP3 and VP1 using a method described by Harvala et al. $(13,14)$. The amplified PCR product was sequenced by Sanger's method using the same primers used for nested PCR. The sequence analysis identified the same 250-base pair (bp) sequences from all samples. A Basic Local Alignment Search Tool (BLAST) search revealed that these fragments were $98 \%$ identical to the sequences of other HPeV3.

Cerecoxib was initiated at a dose of $100 \mathrm{mg}$ twice a day, which improved his fever and muscle pain. He was discharged from the hospital on day 9 of admission with no fever or pain.

\section{Discussion}

Mild-to-moderate diffuse myalgia is a common symptom of any acute viral infection. In our case, however, medical attention was sought because the muscle pain was so severe that the patient was unable to get up from a chair or walk. In such cases, several differential diagnoses should be considered before concluding a simple viral infection. The etiology of myalgia can often be categorized based on the symptoms, whether they are diffuse or focal. In the present case, the patient had diffuse muscle pain predominantly in the extremities. In addition to the possibility of a systemic infection, many other potential causes were likely as well, including non-inflammatory pain syndrome, such as fibromyalgia or chronic fatigue syndrome; rheumatic disease, such as polymyalgia rheumatica; autoinflammatory disease, such as polymyositis; endocrine disorders, such as thyroid disease; adverse effects of medications; or psychiatric disorders, including depression. However, considering the patient's age, clinical data, and history, these causes were all deemed unlikely. A history of contact with his child, who had an acute respiratory infection, and the clinical symptoms of a fever and sore throat suggested that a viral infection was the most likely cause of his myalgia. Considering the extremely severe myalgia associated with a viral infection, epidemic myalgia was clinically diagnosed.

A typical characteristic of epidemic myalgia, also known as Bornholm disease, is the sudden onset of extreme pain in the chest or upper abdomen, sometimes associated with a fever or sore throat. It thus sometimes manifests as epidemic pleurodynia. Coxsackievirus and Echovirus have been implicated as the causes of Bornholm disease. However, our study patient had severe pain predominantly in the extremities, resulting in his being unable to stand or walk. Given the findings, a clinical diagnosis of epidemic myalgia caused by $\mathrm{HPeV} 3$ infection was suspected. The clinical presentation was extremely severe, and only a few reports of this diagno- sis in adults have been published from limited areas in Japan. The suspected diagnosis was confirmed through the detection of the partial sequence of $\mathrm{HPeV} 3$ in throat swabs and stool and serum specimens using reverse transcriptionPCR (RT-PCR).

In 2016, we isolated partial sequences of HPeV3 from children and adults in other regions of Japan, including Kagoshima, Kyoto, Tokyo, and Okinawa, which appear to be classified into the same cluster as demonstrated in the phylogenetic tree (Figure). This suggests that HPeV3 infection was prevalent in several areas of Japan in 2016. Reported cases of epidemic myalgia associated with HPeV3 infection confirmed by either or both PCR or an increase in neutralizing antibodies against HPeV3 are summarized in Table 2. In 2016, 13 cases of epidemic myalgia were reported. Most patients with myalgia associated with $\mathrm{HPeV} 3$ infection were between 20 and 40 years of age, which is the child-rearing age range. Many patients had a history of contact with their sick children or spouses, as reported in our case, although we did not isolate $\mathrm{HPeV} 3$ virus from the son of the present patient. Men accounted for $79 \%$ of cases; the underlying reason for this sex difference remains to be determined.

Based on data from the infectious disease surveillance center, HPeV3 epidemics occur every two to three years in Japan (14). Interestingly, the HPeV3 epidemics appear to be closely related to the frequency of reports of epidemic myalgia in Japan. Thus, it has been speculated that an outbreak of HPeV3 among children is a necessary background condition for an outbreak of epidemic myalgia in adults (15). The positive rate for neutralizing antibodies against $\mathrm{HPeV} 3$ has been reported to increase with age until the late teens but seems to decline in older age groups $(9,16)$. Therefore, it has been speculated that individuals between 20 and 40 years old do not have enough neutralizing antibodies, leading to an increase in the prevalence of $\mathrm{HPeV} 3$-associated myalgia among them. If this is the case, elderly people may be more likely to develop HPeV3-associated myalgia; however, no such cases have been reported thus far. This may be, at least in part, attributable to the reduced chances of contact between elderly individuals and sick children infected with HPeV3 virus, although whether the elderly are less susceptible to $\mathrm{HPeV} 3$ infection or the development of epidemic myalgia due to $\mathrm{HPeV} 3$ infection remains unclear.

Regarding the symptoms, it should be noted that severe myalgia and muscle weakness predominantly occur in the proximal upper and/or lower limbs but are not confined to the torso, as described for epidemic myalgia associated with Bornholm disease caused by Coxsackievirus and Echovirus. One possible mechanism that may underlie such severe myalgia induced by $\mathrm{HPeV} 3$ infection has been reported by Nakamura et al. (17). The authors measured several cytokines and found that the interleukin-6 (IL-6) level was significantly elevated in patients, suggesting that an elevated IL-6 level may serve as a characteristic finding of severe myalgia. However, the reason underlying the exclusive association be- 


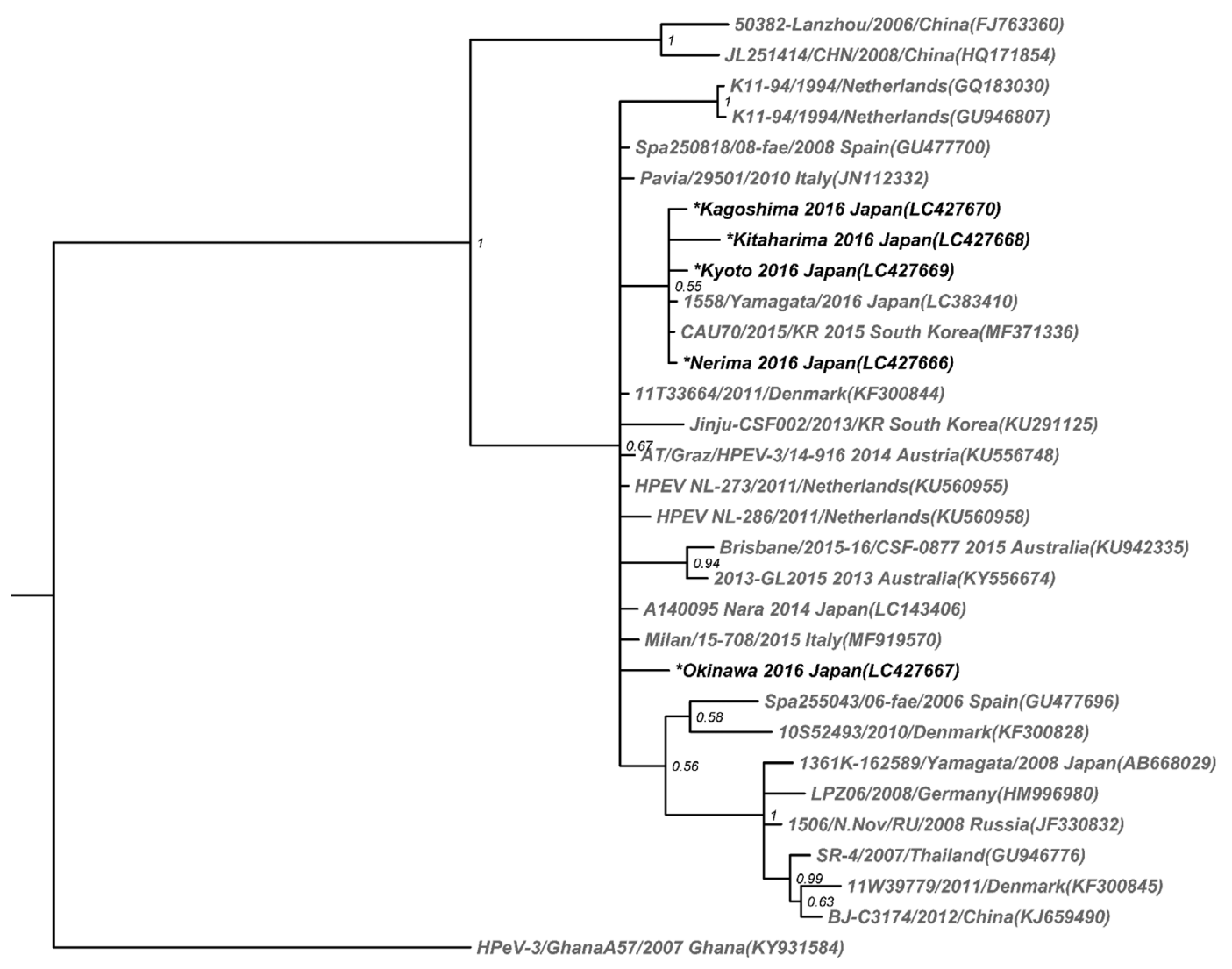

0.04

Figure. A Bayesian phylogenetic tree of HPeV3, including the strain isolated from our case (indicated by Kitaharima 2016) and from other areas, was constructed with the software program MrBayes v.3.4. The asterisks indicate the identified strains. The strains detected in Kagoshima and Kyoto in 2016 were isolated from adults with myalgia, whereas those from Nerima and Okinawa were isolated from infants under one year of age in 2016. The bar indicates genetic distance, the branch lengths are proportional to the differences, and the posterior probability of the branching is shown next to the nodes. GenBank accession numbers are indicated on the tips. HPeV3: human parechovirus type 3

tween $\mathrm{HPeV} 3$ infection and severe myalgia remains unknown, as cytokine levels are elevated in patients with infections induced by other viral infections as well.

At present, the clinical reports of epidemic myalgia associated with $\mathrm{HPeV} 3$ are limited to a few areas in Japan. One potential reason for this may be, at least in part, due to the lack of awareness of this disease and/or access to virological analyses. However, it is still unclear why such severe cases have been exclusively reported from Japan. The phylogenetic tree shows 31 sequences, including 13 European (42\%), 14 Asian (45\%), 3 Australian (10\%), and 1 African $(3 \%)$, and the strains do not show much variation, indicating that a potential viral adaptation exclusive to the Japanese population is unlikely to be the reason. One possible explanation is genetically determined differences between Japanese individuals and those from other countries in the degree of the IL- 6 response to severe stress. Indeed, polymorphisms within the 5 flanking region of $I L-6$, associated with changes in plasma IL-6 levels, have been reported in systemic-onset juvenile chronic arthritis (18). This suggests that the IL-6 response to stressful stimuli is genetically dif- ferent between individuals. Therefore, the innate immune response to HPeV3 and associated symptoms may be linked to genetic variations among human populations.

The present patient exhibited no elevation of CK and only a modest increase in CRP despite his extremely severe muscle pain. The levels of CK and CRP remained normal in at least $24 \%$ and $26 \%$ of the patients with HPeV3-associated myalgia, respectively (Table 2). Given that the CK values increase late (on day 3 or 7 of hospitalization) according to Yamamoto et al. (5), the increase in CK values may have been missed in some cases. Another possible explanation for the lack of any marked increase in CK values is that the inflammation caused by $\mathrm{HPeV} 3$ infection predominantly occurs in the fasciae without severe damage to the muscle (19). Orchiodynia is also a characteristic symptom; 10 out of 30 infected men reported orchiodynia. Although the exact mechanism underlying the development of orchiodynia in these cases was not clarified, swollen testes and peritesticular effusion were revealed by computed tomography (CT) (20). Patients with HPeV3-associated myalgia typically recover within a week; however, non-steroidal anti- 
Table 2. Characteristics of 38 Adult Cases of Epidemic Myalgia Associated with HPeV3 Infection.

\begin{tabular}{|c|c|c|c|c|c|c|c|c|c|c|}
\hline & Age & Sex & Prefecture & Symptom & Season & $\begin{array}{c}\mathrm{CK} \\
\text { elevation }\end{array}$ & $\begin{array}{c}\text { CRP } \\
\text { elevation }\end{array}$ & Orchiodynia & $\begin{array}{c}\text { Sick } \\
\text { contact }\end{array}$ & Reference \\
\hline 1 & 36 & M & Yamagata & myalgia, weakness, fever & June 2008 & - & + & - & NM & 4 \\
\hline 2 & 31 & M & Yamagata & myalgia, weakness, fever, sore throat & June 2008 & - & + & - & NM & 4 \\
\hline 3 & 43 & M & Yamagata & myalgia, weakness, fever, sore throat & June 2008 & - & + & - & NM & 4 \\
\hline 4 & 30 & $\mathrm{~F}$ & Yamagata & myalgia, weakness, fever & June 2008 & + & - & & NM & 4 \\
\hline 5 & 28 & M & Yamagata & $\begin{array}{c}\text { myalgia, weakness, fever, sore throat, } \\
\text { orchiodynia }\end{array}$ & June 2008 & - & + & + & NM & 4 \\
\hline 6 & 39 & $\mathrm{~F}$ & Yamagata & myalgia, weakness, fever, sore throat & June 2008 & + & + & & NM & 4 \\
\hline 7 & 36 & M & Yamagata & myalgia, weakness, fever, sore throat & July 2008 & + & + & - & NM & 4 \\
\hline 8 & 35 & M & Yamagata & myalgia, weakness, fever, sore throat & July 2008 & + & + & - & NM & 4 \\
\hline 9 & 38 & M & Yamagata & myalgia, weakness, fever, sore throat & July 2008 & + & - & - & NM & 4 \\
\hline 10 & 38 & $\mathrm{~F}$ & Yamagata & myalgia, weakness, fever, sore throat & July 2008 & + & + & & NM & 4 \\
\hline 11 & 37 & $\mathrm{~F}$ & Yamagata & myalgia, weakness, seizures & July 2008 & + & - & & NM & 4 \\
\hline 13 & 36 & M & Yamagata & $\begin{array}{c}\text { myalgia, weakness, fever, sore throat, } \\
\text { orchiodynia }\end{array}$ & July 2008 & + & + & + & NM & 4 \\
\hline 14 & 55 & M & Yamagata & $\begin{array}{c}\text { myalgia, weakness, fever, sore throat, } \\
\text { orchiodynia }\end{array}$ & August 2008 & + & + & + & NM & 4 \\
\hline 15 & 21 & M & Yamagata & $\begin{array}{l}\text { myalgia, weakness, fever, cough, } \\
\text { nasal discharge, diarrhea }\end{array}$ & June 2008 & + & - & - & - & 21 \\
\hline 16 & 37 & M & Yamagata & myalgia, weakness, fever & July 2008 & + & - & - & - & 21 \\
\hline 17 & 33 & M & Yamagata & $\begin{array}{c}\text { myalgia, weakness, fever, sore throat, } \\
\text { diarrhea }\end{array}$ & July 2008 & + & + & - & - & 21 \\
\hline 18 & 41 & M & Yamagata & $\begin{array}{c}\text { myalgia, weakness, rash, sore throat, } \\
\text { orchiodynia }\end{array}$ & July 2011 & + & + & + & + & 21 \\
\hline 19 & 31 & M & Yamagata & myalgia, weakness, fever & July 2011 & + & + & - & + & 21 \\
\hline 20 & 41 & M & Yamagata & myalgia, weakness, fever, sore throat & July 2011 & + & + & - & - & 21 \\
\hline 21 & 38 & M & Yamagata & $\begin{array}{l}\text { myalgia, weakness, fever, } \\
\text { orchiodynia }\end{array}$ & July 2011 & + & + & + & - & 21 \\
\hline 23 & 44 & M & Yamagata & myalgia, weakness, fever & August 2014 & + & - & - & + & 21 \\
\hline 24 & 30 & $\mathrm{~F}$ & Yamagata & $\begin{array}{c}\text { myalgia, wekness, fever, headache, } \\
\text { diarrhea }\end{array}$ & August 2014 & + & - & & + & 21 \\
\hline 25 & 22 & M & Osaka & $\begin{array}{l}\text { fever, headache, arthralgia, myositis, } \\
\text { hypotention, pharyngitis }\end{array}$ & September 2014 & + & - & - & + & 5 \\
\hline 26 & 37 & $\mathrm{~F}$ & Yamagata & myalgia, weakness, fever, sore throat & July 2016 & + & - & & + & 21 \\
\hline 27 & 44 & M & Yamagata & myalgia, weakness & August 2016 & + & + & - & - & 21 \\
\hline 28 & 31 & M & Yamagata & $\begin{array}{l}\text { myalgia, weakness, fever, } \\
\text { pharyngitis, orchiodynia }\end{array}$ & August 2016 & + & - & + & + & 21 \\
\hline 29 & 43 & M & Yamagata & myalgia, weakness, fever, pharyngitis & August 2016 & + & + & - & - & 21 \\
\hline 30 & 39 & M & Yamagata & $\begin{array}{c}\text { myalgia, weakness, fever, stomatitis, } \\
\text { orchiodynia }\end{array}$ & August 2016 & + & + & + & + & 21 \\
\hline 31 & 50 & M & Yamagata & myalgia, weakness, fever & August 2016 & + & + & - & NM & 21 \\
\hline 32 & 31 & $\mathrm{~F}$ & Yamagata & myalgia, weakness, fever & August 2016 & - & + & & + & 21 \\
\hline 33 & 28 & $\mathrm{~F}$ & Osaka & $\begin{array}{c}\text { myalgia, weakness, fever, arthralgia, } \\
\text { pregnant }\end{array}$ & November 2016 & - & + & & + & 19 \\
\hline 34 & 30 & $\mathrm{M}$ & Kanagawa & myalgia, weakness, orchiodynia & $\begin{array}{l}\text { September- October } \\
2016\end{array}$ & + & NM & + & + & 6 \\
\hline 35 & 38 & M & Kanagawa & myalgia, sore throat, tong pain & $\begin{array}{l}\text { September- October } \\
2016\end{array}$ & + & NM & - & + & 6 \\
\hline 36 & 39 & M & Kanagawa & myalgia, weakness, fever & $\begin{array}{l}\text { September- October } \\
2016\end{array}$ & - & NM & - & + & 6 \\
\hline 37 & 32 & M & Fukushima & $\begin{array}{l}\text { myalgia, orchiodynia, fever, sore } \\
\text { throat, diarrhea }\end{array}$ & September 2016 & - & + & + & + & 17 \\
\hline 38 & 42 & M & Hyogo & $\begin{array}{l}\text { myalgia, weakness, fever, } \\
\text { orchiodynia, sore throat }\end{array}$ & July 2016 & - & + & + & + & this case \\
\hline
\end{tabular}

HPeV3: human parechovirus type 3, M: male, F: female, NM: not mentioned 
inflammatory drugs are effective for relieving severe symptoms (21).

In conclusion, we presented the case of a patient with epidemic myalgia associated with $\mathrm{HPeV} 3$ infection in Hyogo Prefecture, Japan. The sudden onset of extreme pain in the extremities, which made it difficult for the patient to stand or walk, accompanied by a fever, sore throat, and orchiodynia, resembled the characteristic clinical presentation of $\mathrm{HPeV} 3$-associated epidemic myalgia. Owing to the spread of $\mathrm{HPeV} 3$ infection among children in various areas in Japan, HPeV3-associated epidemic myalgia should be considered when patients present with such severe symptoms in a clinical context. Furthermore, tracking the prevalence of $\mathrm{HPeV} 3$-associated epidemic myalgia in various areas of Japan is important for improving the public health response during an outbreak of this disease.

The authors state that they have no Conflict of Interest (COI).

\section{Financial Support}

This research was partly supported by AMED under Grant Number JP19fk0108084j0501 (to T.F.).

\section{Acknowledgement}

We would like to thank Ms. Masami Konagaya for her technical support.

\section{References}

1. Warin JF, Davies JB, Sanders FK, Vizoso AD. Oxford epidemic of Bornholm disease, 1951. Br Med J 20: 1345-1351, 1953.

2. Williams WO. Bornholm disease survey 1956, 1957 and 1958. J Coll Gen Pract 4: 181-213, 1961.

3. Romero JR, Modlin JF. Coxsackieviruses, Echoviruses, and numbered Enteroviruses. In: Mandell, Douglas, and Bennett's principles and practice of infectious diseases. 8th ed. Elsevier, Philadelphia, PA, 2015: 2080-2090.

4. Mizuta K, Kuroda M, Kurimura M, et al. Epidemic myalgia in adults associated with Human Parechovirus type 3 infection, Yamagata, Japan, 2008. Emerg Infect Dis 18: 1787-1793, 2012.

5. Yamamoto SP, Kaida A, Naito $T$, et al. Human parechovirus infections and child myositis cases associated with genotype 3 in Osaka City, Japan, 2014. J Med Microbiol 64: 1415-1424, 2015.

6. Sano T, Kadekaru S, Watanabe S, et al. Detection of human parechovirus 3 from primary school students and adults with myalgia, June to October 2016-Kanagawa Prefecture. Infect Agents Surveill Rep 38: 127-128, 2017 (in Japanese).
7. Stanway G, Joki-Korpela P, Hyypiä T. Human parechovirusesbiology and clinical significance. Rev Med Virol 10: 57-69, 2000.

8. Esposito S, Rahamat-Langendoen J, Ascolese B, Senatore L, Castellazzi L, Niesters HGM. Pediatric parechovirus infections. J Clin Virol 60: 84-89, 2014.

9. Ito M, Yamashita T, Tsuzuki H, Takeda N, Sakae K. Isolation and identification of a novel human parechovirus. J Gen Virol 85: 391398, 2004.

10. Harvala H, Wolthers KC, Simmonds P. Parechoviruses in children: understanding a new infection. Curr Opin Infect Dis 23: 224-230, 2010.

11. de Crom SC, Rossen JWA, van Furth AM, Obihara CC. Enterovirus and parechovirus infection in children: a brief overview. Eur $\mathrm{J}$ Pediatr 175: 1023-1029, 2016.

12. Khatami A, McMullan BJ, Webber M, et al. Sepsis-like disease in infants due to human parechovirus type 3 during an outbreak in Australia. Clin Infect Dis 60: 228-236, 2015.

13. Harvala H, Robertson I, McWilliam EC, et al. Epidemiology and clinical associations of human parechovirus respiratory infections. J Clin Microbiol 46: 3446-3453, 2008.

14. Aizawa Y, Saitoh A. Human parechoviruses. Uirusu (Viruses) 65: 17-26, 2015 (in Japanese).

15. Mizuta K, Yamakawa T, Nagasawa $H$, et al. Epidemic myalgia associated with human parechovirus type 3 infection among adults occurs during an outbreak among children: findings from Yamagata, Japan, in 2011. J Clin Virol 58: 188-193, 2013.

16. Tanaka S, Aoki Y, Matoba Y, et al. Seroepidemiology of human parechovirus types 1, 3, and 6 in Yamagata, Japan, in 2014. Microbiol Immunol 60: 854-858, 2016.

17. Nakamura K, Saito K, Hara Y, et al. Severe epidemic myalgia with an elevated level of serum interleukin- 6 caused by human parechovirus type 3: a case report and brief review of the literature. BMC Infect Dis 18: 381, 2018.

18. Fisherman D, Faulds G, Jeffery R, et al. The effect of novel polymorphisms in the interleukin-6 (IL-6) gene on IL-6 transcription and plasma IL-6 levels, and an association with systemic-onset juvenile chronic arthritis. J Clin Invest 102: 1369-1376, 1998.

19. Shinomoto M, Kawasaki T, Sugahara T, et al. First report of human parechovirus type 3 infection in a pregnant woman. Int J Infec Dis 59: 22-24, 2017.

20. Tanaka S, Kunishi Y, Ota M, et al. Severe human parechovirus Type 3 infection in adults associated with gastroenteritis in their children. J Infect Dis 49: 772-774, 2017.

21. Yamakawa T, Mizuta K, Kurokawa K, et al. Clinical characteristics of 17 adult patients with epidemic myalgia associated with human parechovirus type 3 infection. Clin Neurol 57: 485-491, 2017 (in Japanese).

The Internal Medicine is an Open Access journal distributed under the Creative Commons Attribution-NonCommercial-NoDerivatives 4.0 International License. To view the details of this license, please visit (https://creativecommons.org/licenses/ by-nc-nd/4.0/).

(C) 2020 The Japanese Society of Internal Medicine Intern Med 59: 739-744, 2020 